\section{Peer review in biomedical publication}

The second international congress on peer review in biomedical publication will be held in September 1993.

During six half-day sessions the following topics will be discussed: mechanisms of peer review and editorial decision making in different journals, including 'blinded' review; relation between authors, editors, and reviewers, and how each is educated, selected, and evaluated; allocation of responsibility for published material; quality assurance and standards for reviewers and editors; breakdowns, weaknesses, and biases; fraud and scientific misconduct; peer review in other disciplines; and peer review of grant proposals.

The subject of the congress is biomedical publication, but scholars from other disciplines are urged to participate. Future notification will call for abstracts and announce the exact date and site of the congress. The deadline for submission of abstracts is 1 January 1993.

For more information please contact: Jane Smith, European Coordinator, BMJ, BMA House, Tavistock Square, London WC1H 9JR.

\section{Clinical epidemiology: principles, methods, and applications}

The department of epidemiology/health care research of the University of Limburg, Maastricht, The Netherlands, will run a clinical epidemiology course from 30 September to 4 October 1991. A reasonable proficiency in English is required but prior knowledge of clinical epidemiology is not necessary.

Topics will include: occurrence measures for disease events, validity and reliability of diagnosis prediction, and measurement of prognosis implementation of study results in daily practice. The course is aimed at health care professionals involved in day to day patient management (doctors, nurses, physiotherapists), their teachers, and those who take part in health care research.

Further details from: F Hein, Clinical Epidemiology Course, Faculty of Health Sciences, University of Limburg, PO Box 616, 6200 MD Maastricht, The Netherlands. Tel: 31438 87396. Fax: 3143255643.

\section{Medicine and musicians}

A symposium on medicine and musicians will be held in the newly restored Governor's Hall at St Thomas's Hospital, London, arranged by Dr John A Mathews, on 11 October 1991. It has been arranged in conjunction with the British Association for Performing Arts Medicine. Registration fee is $£ 55$ (£45 until 1 August 1991).

For further details please apply to the course administrator, Mrs Wendy Mathews, Rheumatology Department, St Thomas's Hospital, London SE1 7EH.

\section{Arthritis: a simple examination for early detection and diagnosis}

A 28 minute VHS videocassette entitled Arthritis: a simple examination for early detection and diagnosis, has been made by Dr I D Griffiths, BSc, MB, BS, FRCP, lecturer in rheumatology, department of medicine, University of Newcastle. Upon Tyne.

This video - an introduction to the examination of the musculoskeletal system-is designed for use by undergraduate medical students. The need to examine patients is stressed, and a simple quick method of evaluation is demonstrated. This is placed within the context of both normality and abnormality. The programme ends with an outline of the principles of more detailed evaluation of a 'target' joint.

Arthritis: a simple examination for early detection and diagnosis is available for purchase at $£ 44.85$ (p \& p and VAT inc). Seven day rental or preview is $£ 16 \cdot 10$ ( $p \& p$ and VAT inc), but this charge will be deducted from the purchase price if an order is received within 28 days of the original transaction.

Orders should be sent to: Mrs D A Croydon, Audio Visual Centre, University of Newcastle upon Tyne, The Medical School, Framlington Place, Newcastle upon Tyne NE2 4HH. Tel: 0912226000 (ext 6633).

\section{Third international conference on systemic lupus erythematosus}

The third international conference on systemic lupus erythematosus will be held from the 13 to 15 April 1992, at the Queen Elizabeth II Conference Centre, London, United Kingdom.

Its principal aim is to consider the scientific and clinical research characteristics of systemic lupus erythematosus. It will be organised by Industrial Seminars and the conference chairman will be Dr Graham Hughes, Lupus Research Unit, St Thomas's Hospital, London, United Kingdom.

For further information please contact: Gillian Shinar on +44(0)892544027.

\section{4th Scandinavian congress of rheumatology}

The 24th Scandinavian congress of rheumatology will be held in Malmo, Sweden, from 31 May to 3 June, 1992. The scientific language will be English. Participation of non-Scandinavians is welcome.

The programme will be organised mainly in three parallel sessions dealing with basic, clinical, or special interest group topics. There will be an update entitled 'Frontiers in rheumatology', which will be arranged immediately before the opening on 31 May.

For further details please contact: Professor Frank Wollheim, Department of Rheumatology, Lund University Hospital, S-221 85 Lund, Sweden. Tel: 4646172280 or 171603. Fax: 4646128468 . 